\title{
Contextually Appropriate Approach to Quality in Early Childhood Settings
}

\author{
Natalie Wade \\ University of Tennessee at Martin, Martin, USA
}

\begin{abstract}
Following will be a comparison of two different positions on quality in early childhood settings as it applies to an international platform. The two positions that will be compared are DAP (developmentally appropriate practice) as defined by NAEYC (the National Association for the Education of Young Children) and contextually appropriate approach as advocated by many in the international early childhood community. The discussion will begin with a definition of contextually appropriate approach to quality. This will be followed by a comparison of the two positions on ideals of quality with specific examples from various cultures. Then the discussion will turn to my personal perspective on DAP as it relates to my own culture. Finally, it will conclude with a look at the 2006 edition of Developmentally Appropriate Practice (Copple \& Bredekamp, 2006) and how the changes made have or have not translated into a more diverse ideal of early childhood quality.
\end{abstract}

Keywords: contextually appropriate practice, childcare, standards, rating scales, cultural diversity, DAP (developmentally appropriate practice)

\section{Modern Early Childhood Theory and the Western World}

Child development theory in its infancy evolved around the same time as the Industrial Revolution in the Western world. The founding theorists were all of Euro-American descent, and the theories they proposed followed with Western culture. As child development theory evolved it continued to have its foundation in Western culture. Now in the 21st century, countries outside of the Western world are beginning to understand the importance of early childhood (Fleer, 2006). However, applying Western child development theory presents cultural difficulties. This has led to the rise of what some have labeled as contextually appropriate approach to quality. This approach takes into consideration much more than pure child development theory (Woodhead, 1998). The social context is given much more importance "than a phenomenon to be analysed for clues about the individual, but is something that shapes and is shaped by those who participate in it" (Edwards, 2004). Different stakeholders of quality are acknowledged in this position. Parents, administrators, teachers/providers, children, and society at large all have a stake in the definition of quality for early childhood education (Ho, 2008). It is impossible to take culture out of the equation (Han \& Thomas, 2010).

This position also acknowledges that children can learn in multiple ways. Learning through play is not seen as the only way to teach children. How children are taught must be based on the cultural context of these children's families and communities. Children outside the Western world do not have access to the materials available to the children in the Western world. Yet these children can become competent citizens of their 
environment through the teachers and resources available to them. Quality has to be a relative term and cannot be universally defined in the international community (Woodhead, 1998).

\section{Early Childhood Outside the Western World}

Outside of the Western world, some aspects of DAP prove difficult to implement. Some of the best examples of these disparities come from the work of Woodhead (1998):

The annual budget for a US Headstart programme is calculated to average about $\$ 2600$ for each child. In India, this sort of money would pay the annual salaries of at least 150 nursery workers.

Staffing ratios in British nursery education are calculated at around 15:1. Kenyan nursery classes (which include children as young as three) are regularly attended by 40 children, and it is not uncommon for there to be as many as 60 children, all in one classroom, under the supervision of one adult.

Preschool children in Europe and North America are surrounded with an abundance of play materials to support every conceivable form of play and learning, to which they generally have free access. In much of the rest of the world, early childhood programmes function with little or no manufactured equipment at all. Where a few wooden blocks or puzzles are available, children may only occasionally be given the opportunity to play with them-They are far too precious to permit unrestricted play.

These examples of external disparities are the most obvious challenges. However, more subtle disparities also exist. Different cultures put different emphasis of importance on various traits. For example, high-context cultures, such as China, Japan, and Korea, place more emphasis on conforming than individuality. The opposite is true of low-context cultures including most of Europe and the US. The parts of DAP that involve choice or even self-esteem as defined by Western culture create problems for people from high-context cultures (Gestwicki, 2007). Do these people have lower self-esteem or make poor choices because they do not adhere to Western ideals? It is a dangerous proposition to suppose that Western ideals are superior to the rest of the world (Singer, 1998).

\section{My Background-Homeschooling and a Business Degree}

Two aspects of my past define who I am as a childcare professional, and interestingly enough, neither is my training in early childhood theory. The first is my 13 years of homeschooling experience. As a homeschooling parent, I had to learn what I believed about education and my worldview in order to sift through thousands of variations of educational curriculum available. This process refined me as an individual and made me a much more effective teacher. I do not try to implement a style of curriculum that does not fit my philosophy or worldview because I have learned that what you teach must be from the heart if it is to have the most impact. The second aspect involves my business degree. As a business major, finding your niche as a business is stressed above almost every other aspect. A business that establishes its own niche on the market has a much greater chance of success. The foundation for my business model comes from these two aspects. As an Evangelical, socially conservative Christian, I noticed during my homeschooling days that a lot of early childhood theory clashes with my personal beliefs. The area where I live is heavily populated by Evangelical, socially conservative Christians. Therefore, there exists in this area a niche for preschool specifically designed to meet the needs of this population. No other preschool in this area dares to defy DAP. I set out to fill this void using the knowledge and skills I acquired as a homeschooling mom. 


\section{My Personal Cultural Background}

Even though I live in the United States, my own personal culture clashes with DAP on certain points. The points of contention that exist between my culture and DAP involve almost the same ideals for high-context cultures. The main one I will discuss for this paper is choice. In my culture, obedience is of much more importance than individuality. To quote the Bible, "Behold, to obey is better than sacrifice, and to heed than the fat of rams" (1 Samuel 15:22b). In my worldview, free choice does not produce children who make good choices. Boundaries and realistic expectations produce children who make good choices. Therefore, the level of choice advocated in Western early childhood theory comes into direct conflict with my culture. I do not agree with treating children as equals with adults. "Empowering children" by offering them choices all day long (C. A. Decker, J. R. Decker, Freeman, \& Knopf, 2009) does not prepare them for a world full of boundaries and expectations which will not take into account their personal preferences. I truly believe what will be produced is an entitled generation incapable of dealing with the real-world stressors of adult life. Am I right or wrong? According to my culture, I am right. Cultures rarely agree with one another making universal standards of quality a nearly impossible proposition (Woodhead, 1998).

\section{The Conundrum of the Revised Standards and the New Scale}

In doing the research for this paper, I pulled out my copy of the 2006 revised edition of DAP (Copple \& Bredekamp, 2006). I was shocked to find a lot of the concepts for contextually appropriate approach in the revised edition. However, I have seen no evidence of the implementation of these revised ideals in the daily functioning of the early childhood world. In the state of Tennessee, family/group homes have recently had to switch from FDCERS (the Family Day Care Ratings Scale) (Harms \& Clifford, 1989) for assessment to FCCERS-R (the Family Child Care Environmental Rating Scale—Revised) (Harms, Cryer, \& Clifford, 2007). The interpretation of this scale among the assessors does not leave any room for diversity of thought. My program was penalized because I put too many boundaries on the children's choices. The exact same structure existed from the previous year. Under the FDCERS scale, the previous year I was not penalized for that reason. The older scale seemed to leave more room for diversity of thought than does the new scale. The older scale rather than the newer scale seems to fit with the principles laid out in the revised edition of DAP. Instead of embracing diversity of thought as laid out in the revised edition of DAP, the new scale seems to be moving in the opposite direction.

\section{No Room for Innovation}

As a businessperson, I find the standards stifling of innovation. It seems to us in the field that the standards push for a one-size-fits-all cookie-cutter preschool/childcare. The next generation of innovators such as Montessori or High-Scope does not have an environment conducive to development. I do not believe that the writers of the standards intend for this to be a reality, but it is the realitynonetheless. The model for my childcare involves individualized instruction for all of the children. However, because I allow children of the same age to vary so widely in their instruction, I have been penalized. The main point of contention I have found with DAP comes with children that fall on either side of the fringe of the normal curve of development. Children with developmental delays and that fall on the autistic spectrum have a hard time functioning within the standards. On the other hand, children that are advanced or gifted fall so far above the standards that I have been accused of pushing too much academic content that is not developmentally appropriate. As the mother of 
a gifted child, I understand that these children must be challenged or they will become a behavioral challenge. Holding advanced or gifted children back because they do not fit the mold offends me as the mother of a gifted child. Parents of children with developmental delays or fall on the autistic spectrum feel the same way in reverse. Pushing these children or forcing them to be in environments that do not meet their needs remains just as offensive. DAP makes no room for a childcare with an innovative model outside of the underlying philosophy that governs its standards.

\section{Conclusion}

In conclusion, in the world outside of the United States and Europe much debate surrounds the concept of DAP. In response, a great deal of the international early childhood community has called for standards of quality that take into consideration diversity of culture. The NAEYC has responded with a revised edition of DAP. However, the implementation of those changes has not been seen in the day-to-day workings of the early childhood community. Standards for accreditation and ratings scales do not reflect the revised position. Until these tools are also revised to allow for more diversity of thought, the debate in the international community as well as the United States and Europe will continue.

\section{References}

Copple, C., \& Bredekamp, S. (2006). Developmentally appropriate practice in early childhood programs. Washington, D.C. National Association for the Education of Young Children.

Decker, C. A., Decker, J. R., Freeman, N. K., \& Knopf, H. T. (2009). Planning and administering early childhood programs. Upper Saddle River, New Jersey \& Columbus, Ohio. Pearson.

Edwards, E. (2004). Understanding context, understanding practice in early education. European Early Childhood Education Research Journal, 12(1), 85-102.

Fleer, M. (2006). The cultural construction of child development: Creating institutional and cultural intersubjectivity. International Journal of Early Years Education, 14(2), 127-140.

Gestwicki, C. (2007). Home, school, and community relations. Clifton Park, New York. Thomas Delmar Learning.

Han, H. S., \& Thomas, M. S. (2010). No child misunderstood: Enhancing early childhood teachers' multicultural responsiveness to the social competence of diverse children. Early Childhood Education, J(37), 469-476.

Harms, T., \& Clifford, R. M. (1989). Family day care rating scale. New York. Teachers College Press.

Harms, T., Cryer, D., \& Clifford, R. M. (2007). Family child care environment rating scale-Revised edition. New York. Teachers College Press.

Ho, C. W. D. (2008). Exploring the definitions of quality early childhood programmes in a market-driven context: Case studies of two Hong Kong preschools. International Journal of Early Years Education, 16(3), 223-236.

Singer, E. (1998). Shared care for children. In M. Woodhead, D. Faulkner, \& K. Littleton (Eds), Cultural worlds of early childhood (64-84). London, Routledge.

Woodhead, M. (1998). "Quality" in early childhood programmes-A contextually appropriate approach. International Journal of Early Years Education, 6(1), 5-17. 